\title{
Demethylation of SOCS1 mediates its abnormally high expression in ovarian cancer
}

\author{
XUEJIAO LI ${ }^{1}$, CHUIMIAO KONG ${ }^{2}$, YUCHUN FAN ${ }^{2}$, JIA LIU $^{2}$, WEIYUAN LU ${ }^{2}$, \\ CAIYUN MENG ${ }^{1}$, AIMEI LI ${ }^{1}$, AIXIA ZHAI ${ }^{1}$, BINGQING YAN ${ }^{1}$, WUQI SONG $^{1}$ and XU HAN ${ }^{2}$ \\ ${ }^{1}$ Department of Microbiology, Harbin Medical University, Wu Lien-Teh Institute, The Heilongjiang Key Laboratory of \\ Immunity and Infection, The Key Laboratory of Pathogenic Biology, Heilongjiang Higher Education Institutions; \\ ${ }^{2}$ Department of Gynecology Endoscopy Section, The First Affiliated Hospital of Harbin \\ Medical University, Harbin, Heilongjiang 150081, P.R. China
}

Received June 20, 2018; Accepted April 26, 2019

DOI: $10.3892 / \mathrm{ol} .2019 .10451$

\begin{abstract}
The present study aimed to investigate the association between methylation and the high expression of the suppressor of cytokine signaling 1 (SOCS1) in ovarian cancer by detecting the methylation rate and the degree of expression. The present study investigated the expression of SOCS1 mRNA and SOCS1 protein in ovarian cancer and normal ovary tissues using reverse transcription-quantitative polymerase chain reaction (PCR) and immunohistochemistry, and the methylation status of the CpG islands of SOCS1 mRNA in ovarian cancer tissue were examined using a methylation-specific PCR. The expression levels of SOCS1 mRNA in ovarian cancer specimens were significantly increased compared with that in the normal ovary tissues $(\mathrm{P}=0.0215)$. Consistent with this, the expression levels of SOCS1 protein in ovarian cancer specimens were significantly increased, while the methylation rate of SOCS1 mRNA was significantly decreased compared with that in the normal ovary tissues. Therefore, it may be concluded that the low methylation rate of SOCS1 mRNA in ovarian cancer increased the expression of SOCS1 mRNA, which may serve a role in the development of ovarian cancer.
\end{abstract}

Correspondence to: Dr Wuqi Song, Department of Microbiology, Harbin Medical University, Wu Lien-Teh Institute, The Heilongjiang Key Laboratory of Immunity and Infection, The Key Laboratory of Pathogenic Biology, Heilongjiang Higher Education Institutions, 157 Health Road, Harbin, Heilongjiang 150081, P.R. China

E-mail: songwuqi@aliyun.com

Dr Xu Han, Department of Gynecology Endoscopy Section, The First Affiliated Hospital of Harbin Medical University, 199 Dazhi Street, Harbin, Heilongjiang 150081, P.R. China

E-mail: hanxu_hyd@163.com

Key words: suppressor of cytokine signaling 1, reverse transcription-quantitative polymerase chain reaction, gene expression, ovarian cancer, methylation

\section{Introduction}

Ovarian cancer has the third highest incidence of all malignant tumor types in the female reproductive system globally, but is the leading cause of cancer-associated mortality worldwide (1). A variety of mechanisms may underlie the occurrence and development of ovarian cancer; however, further investigation is required. Novel diagnostic and prognostic markers and therapeutic targets are urgently required. Suppressor of cytokine signaling (SOCS) is a class of negative regulators that block the cytokine signaling process, and are also negative regulators of Janus kinase (JAK) and signal transducers and activators of transcription (STAT), which are involved in the cytokine signaling pathway (2). Among the SOCS family, SOCS1 is the most important cytokine that induces the JAK/STAT signaling pathway $(3,4)$, and its main function is to regulate the activation of STAT3 and STAT5 $(5,6)$. Altered SOCS1 expression has been reported in a wide range of human cancer types and may function as a diagnostic or prognostic biomarker. In a study by Scutti et al (7), the potential for the mutation and abnormal expression of the SOCS1 gene were observed in liver cancer, non-small cell lung cancer and malignant melanoma. The mutation usually occurs in the promoter and the first exon region, and often in the gene regulatory region at the 5 ' end of the gene; the abnormal methylation of the SOCS1 gene may be involved in the occurrence and development of tumors (8). However, this phenomenon has not been clearly reported in ovarian cancer. Therefore, the aim of the present study was to determine the methylation status and differential expression of the CpG island of the SOCS1 gene in ovarian cancer and normal ovarian tissue. We also investigated the role of the abnormal methylation and expression of SOCS1 in ovarian cancer, and the potential underlying mechanisms.

\section{Materials and methods}

Patients and samples. A total of 26 ovarian cancer samples and 8 normal ovarian tissues were obtained from patients who underwent laparoscopic oophorectomy at The First Clinical Hospital of Harbin Medical University (Harbin, China) 
between 2014 and 2016. All patients, with a median age of 40 years (age range, 35-45), were women and were confirmed to have ovarian cancer by immunohistochemistry (IHC) testing. According to the classification of the International Federation of Gynecology and Obstetrics in 2009 (9), there were 6 cases of stage I, 4 of stage II, 12 of stage III and 4 of stage IV. The histological grades of the tumor were classified as GI (well-differentiated) in 9 cases, GII (moderately differentiated) in 11 cases and GIII (poorly differentiated) in 6 cases. None of the patients received any radiotherapy or chemotherapy prior to surgery. Before the specimens were collected, informed consent was obtained from patients and their families, and approval was granted from the HMU Medical Science Ethics Committee. All the specimens were stored at $-80^{\circ} \mathrm{C}$ prior to analysis to avoid repeated freeze/thawing.

Methylation-specific polymerase chain reaction (MSP). Using a DNA Extraction kit (Takara Bio, Inc.) according to the manufacturer's protocol, DNA was extracted from the epithelium of the ovarian cancer tissue. Sodium bisulfite modification was performed using a fast DNA bisulfite kit (Takara Bio, Inc.), according to the manufacturer's protocols, following the quantification of the extracted DNA. MSP experiments were performed using the modified genomic DNA and primers for non-methylated SOCS1 (forward, 5'-AACCAAAAAAAT AAACCATAACATC-3' and reverse, 5'-TAGTTGTGTTTA TTGAGGTTGAATG-3') and primers for methylated SOCS1 (forward, 5'-ACCGAA AAA ATA AACCATAACGTC-3' and reverse, 5'-TAGTTGTGTTTATTGAGGTTGAACG-3'). The primers were designed using MethPrimer v2.0 software (http://www.urogene.org/methprimer2) (10). A total volume of $50 \mu \mathrm{l}$ reaction solution containing $2 \mu \mathrm{l}$ DNA, $2 \mu 1$ primers, $25 \mu 1$ SYBR Premix Ex Taq ${ }^{\mathrm{TM}}$ (Takara Bio, Inc.) and $21 \mu \mathrm{ldd} \mathrm{d}_{2} \mathrm{O}$ was used. The ABI PRISM 7500 FRT sequence detection system (Applied Biosystems; Thermo Fisher Scientific, Inc.) was used for the MSP reaction. The thermocycling conditions were $95^{\circ} \mathrm{C}$ for $5 \mathrm{sec}$ and $60^{\circ} \mathrm{C}$ for $30 \mathrm{sec}(40$ cycles). The data were collected and analyzed using the sequence detection system. The sequence detection system was performed using 7500 Software for 7500 and 7500 Fast Real-Time PCR systems v2.3 (Thermo Fisher Scientific, Inc.). In order to standardize the methylated or non-methylated status of the SOCS1 gene in all specimens, all values were expressed as a multiple of the increase or decrease in methylated SOCS1 gene relative to the non-methylated SOCS1 gene. The gene replication values of each specimen were expressed by quantification cycle $(\mathrm{Cq})$. The methylation levels of the gene $(\Delta \mathrm{Cq})$ were expressed as the difference between the methylation value of the SOCS1 gene and the non-methylation value of the SOCS1 gene; the methylation rate of genes was determined using the following formula: $2^{-\left(\text {Cq methylation-Cq non-methylation) } / 2^{-(C q} \text { methylation-Ct non-methylation) }\right.}+1$.

Reverse transcription-quantitative polymerase chain reaction $(R T-q P C R)$. The RNA from the tumor tissues and corresponding normal tissues were extracted using the RNeasy ${ }^{\circledR}$ Mini Kit (Qiagen, Inc.), according to the manufacturer's protocol. The purity ratio of the optical density at 260/280 for the extracted RNA was between 1.9-2.0. RT-qPCR was performed using the SuperScript III kit 2-Step RT-PCR system (Invitrogen; Thermo Fisher Scientific, Inc.). The total
RNA used was $2 \mu \mathrm{g}$. The thermocycling conditions were as follows: $65^{\circ} \mathrm{C}$ for $15,5 \mathrm{~min}$ on ice, $50^{\circ} \mathrm{C}$ for $60 \mathrm{~min}$ and $70^{\circ} \mathrm{C}$ for $15 \mathrm{~min}$. The total reaction volume used was $20 \mu 1$. Applied Biosystems ${ }^{\circledR}$ GeneAmp ${ }^{\circledR}$ PCR System 9700 (Applied Biosystems; Thermo Fisher Scientific, Inc.) was used for the RT-qPCR. A primer set (a pair of qPCR primers for each set) specific for SOCS1 were designed by HaiGene. Primers used were as follows: SOCS1 forward, 5'-GGAACTGCTTTTTCG CCCCTTA-3' and reverse, 5'-AGCAGCTCGAAGAGGCAG TC-3'. $\beta$-actin forward, 5'-AAACTGGAACGGTGAAGG TG-3' and reverse, 5'-GTGGACTTGGGAGAGGACTG-3'. The reaction system was as follows: $2 \mu \mathrm{l}$ cDNA, $4 \mu \mathrm{l}$ SOCS1 primers/ $\beta$-actin primers $(10 \mu \mathrm{M}), 25 \mu \mathrm{l} \mathrm{SYBR}$ Premix Ex $\mathrm{Taq}^{\mathrm{TM}}$ (Takara Bio, Inc.) and $19 \mu \mathrm{l} \mathrm{ddH}_{2} \mathrm{O}$; the total reaction volume was $50 \mu \mathrm{l}$. The ABI PRISM7500 Sequence detection system (Applied Biosystems; Thermo Fisher Scientific, Inc.) was used for the qPCR. The thermocycling conditions were as follows: $95^{\circ} \mathrm{C}$ for $15 \mathrm{sec}$ and $60^{\circ} \mathrm{C}$ for $30 \mathrm{sec}$ (40 cycles). The data was collected and analyzed using the sequence detection system. The sequence detection system was performed using 7500 Software for 7500 and 7500 Fast Real-Time PCR systems 2.3 software (Thermo Fisher Scientific, Inc.). The $\beta$-actin gene was used as an endogenous reference to standardize the relative expression of the SOCS1 gene in all specimens. All values were expressed as a multiple of increase or decrease in SOCS1 mRNA relative to the $\beta$-actin gene. The value of gene replication in each specimen was expressed by the quantification cycle ( $\mathrm{Cq}$ limit cycle number). The differences between the $\mathrm{Cq}$ value of the target gene and the endogenous reference gene $\beta$-actin $(\Delta \mathrm{Cq})$ were determined. The relative expression level of the gene $(\Delta \Delta \mathrm{Cq})$ was expressed as the difference between the $\Delta \mathrm{Cq}$ value of the test specimen and the reference specimen, and the relative expression quantity of the target gene was expressed as $2^{-\Delta \Delta \mathrm{Cq}}(11)$.

IHC analysis. SP link IHC detection kits (biotin-streptavidin HRP detection systems, including goat anti-rabbit secondary antibodies, endogenous peroxidase blockers and normal goat serum) was purchased from Zhongshan Golden Bridge Biotechnology, Co., Ltd. Endogenous peroxidase blockers (100 $\mu$ i; cat. no., SP-9001) was purchased from Zhongshan Golden Bridge Biotechnology, Co., Ltd. and used as blocking agent at room temperature for $10 \mathrm{~min}$. Normal goat serum (100 $\mu$ l; cat. no., SP-9001) was purchased from Zhongshan Golden Bridge Biotechnology, Co., Ltd. and sealed for $15 \mathrm{~min}$ at room temperature. Concentrated rabbit anti-SOCS1 polyclonal antibody (dilution, 1:100; cat. no., SC-9021) was purchased from Santa Cruz Biotechnology, Inc. and used as the primary antibody. A total of $4 \%$ paraformaldehyde (Biosharp; REF:BL539A) was used as a fixative at room temperature for $48 \mathrm{~h}$. The thickness of the sections was $5 \mu \mathrm{m}$. Tissue sections were incubated with primary antibody at $4^{\circ} \mathrm{C}$ overnight. Then, tissue sections were incubated with HRP-conjugated goat anti-rabbit secondary antibody (100 $\mu \mathrm{l}$; cat. no., SP-9001) at $37^{\circ} \mathrm{C}$ for $60 \mathrm{~min}$. The protein location and expression intensity were visualized by 3,3-diaminobenzidine tetrahydrochloride (Boster Biological Technology) and hematoxylin staining at room temperature for $2 \mathrm{~min}$. Finally, a binocular light microscope (x400 magnification) was used to analyze staining. IHC was performed as previously reported (12). The staining results 
for the SOCS1 protein were semi-quantitatively calculated by multiplying the staining intensity and the percentage of positive ovarian cancer cells. The staining result was considered to be positive for SOCS1 if brown-yellow granules were observed and if they were located in the cytoplasm.

The Cancer Genome Atlas (TCGA) gene expression data. The data of ovarian cancer were downloaded by R(TCGA-Assembler $2 \mathrm{R}$ package) from TCGA (http://cancergenome.nih.gov). The expression of SOCS1 in RNA-HTSeq-FPKM-UQ data and overall survival time in clinicopathological parameters were obtained for survival-associated comparison using $\mathrm{R}$ survival package (survival 2.42-6.tar.gz).

Statistical analyses. All quantitative data are expressed as (mean \pm standard deviation). Overall survival time analysis was estimated by the Kaplan-Meier method using the 'survival' package (13) of R (14). The Kaplan-Meier method was performed for visualization purposes and the differences between survival curves were calculated by the log-rank test. Pearson's correlation coefficient test was used for correlation analysis. Statistical analysis was performed using GraphPad Prism v.6 Software (GraphPad Software, Inc.). The unpaired $\mathrm{t}$-test was used for statistical analysis and repeated in triplicate. $\mathrm{P}<0.05$ was considered to indicate a statistically significant difference.

\section{Results}

Methylation rate of SOCS1 $\mathrm{mRNA}$ is decreased in ovarian cancer tissues. MSP was used to detect the relative methylation rate of SOCS1 mRNA in 26 cases of ovarian cancer and 8 cases of normal ovarian tissue. The methylation rate of SOCS1 mRNA was decreased in ovarian cancer tissues compared with that in the normal ovarian tissues. The methylation rate of SOCS1 mRNA in 13 cases of ovarian cancer was $<56 \%$ (Fig. 1 ).

Expression of SOCS1 mRNA is significantly increased in ovarian cancer tissues and its expression level is associated with the overall survival time in ovarian cancer. The present study selected two sections of each sample each from 19 ovarian cancer tissues and 5 normal ovarian specimens. The 19 ovarian cancer samples were taken from 26 ovarian cancer samples, and the 5 normal ovarian samples were taken from 8 normal ovarian samples, then applied RT-qPCR to detect the relative expression of SOCS1 mRNA. The mean value of the relative expression of SOCS1 mRNA in ovarian cancer specimens was 4.0633 , and that in normal ovarian tissues was 1.4681. The expression of SOCS1 was significantly increased in ovarian cancer tissues compared with in the normal tissues $(\mathrm{P}<0.0001$; Fig. 2A). Additionally, in order to further clarify the association between the expression of SOCS1 mRNA and the occurrence and development of ovarian cancer, the present study investigated the expression of SOCS1 mRNA and overall survival time in ovarian cancer using a dataset downloaded from TCGA database. The results of the survival prediction table showed that SOCS1 mRNA expression in ovarian cancer is significantly associated with overall survival time $(\mathrm{P}=0.042$; Fig. $2 \mathrm{~B})$. When the predicted overall survival

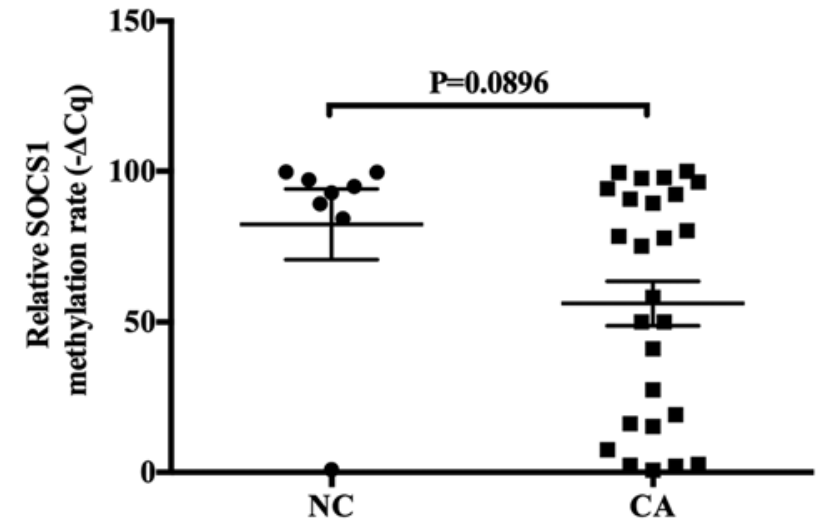

Figure 1. Methylation rate of SOCS1 mRNA in ovarian cancer specimens and normal tissues. $\mathrm{NC}=8$ and $\mathrm{CA}=26$. NC, normal ovarian tissues; CA, ovarian cancer tissues; SOCS1, suppressor of cytokine signaling 1.

time was $0,600,1,200,1,800,2,400$ and 3,000 days, the number of ovarian cancer samples with low SOCS1 expression corresponded to 191, 137, 89, 47, 29 and 13 cases, respectively; the number of ovarian cancer samples with high SOCS1 expression corresponded to 184, 123, 66, 28, 14 and 9 cases, respectively (Fig. 2B).

Expression of SOCS1 protein is positive in ovarian cancer. IHC analysis revealed that the expression of SOCS1 protein was positive in ovarian cancer specimens, but negative for normal ovarian tissue. Positive SOCS1 protein staining presented brown-yellow granules, while negative SOCS1 protein staining presented light yellow granules, which were located in the cytoplasm (Fig. 3).

Methylation of SOCS1 mRNA correlates with the rising expression of the SOCS1 gene. Pearson's correlation coefficient test was performed to study the association between the methylation rate of SOCS1 and the relative expression of SOCS1 mRNA, which was revealed to be negative in ovarian cancer specimens and normal tissues $(\mathrm{P}=0.007$, r-value=-0.663; Fig. 4).

\section{Discussion}

SOCS1 is the earliest discovered member of the SOCS family and a key molecule in cancer development $(5,7,15)$. As a major signal transduction pathway, the JAK/STAT signaling pathway serves a notable role in numerous biological reactions (3). As one of the important negative regulatory proteins in the JAK/STAT signaling pathway, SOCS1 has a strong inhibitory effect on this signaling pathway via three mechanisms: i) It is able to inactivate the N-terminal of JAK kinase by binding its SH2 domain to the phosphorylated tyrosine residues of the target protein, so that signal transduction is inhibited (16). Additionally, the N-terminal of SOCS1 contains a kinase inhibitory region that directly inhibits the activity of JAK tyrosine kinase (17-20); ii) the SOCS1 promoter contains a STAT binding site that can inhibit STAT from binding to the receptor site; and iii) the SOCS cassette is able to interact with elongin $\mathrm{B}$, elongin $\mathrm{C}$, cullin-2 and RINGbox-2, and recruits E3 ubiquitin transferase, to promote the degradation of the 
A

$\mathbf{P}<0.0001$

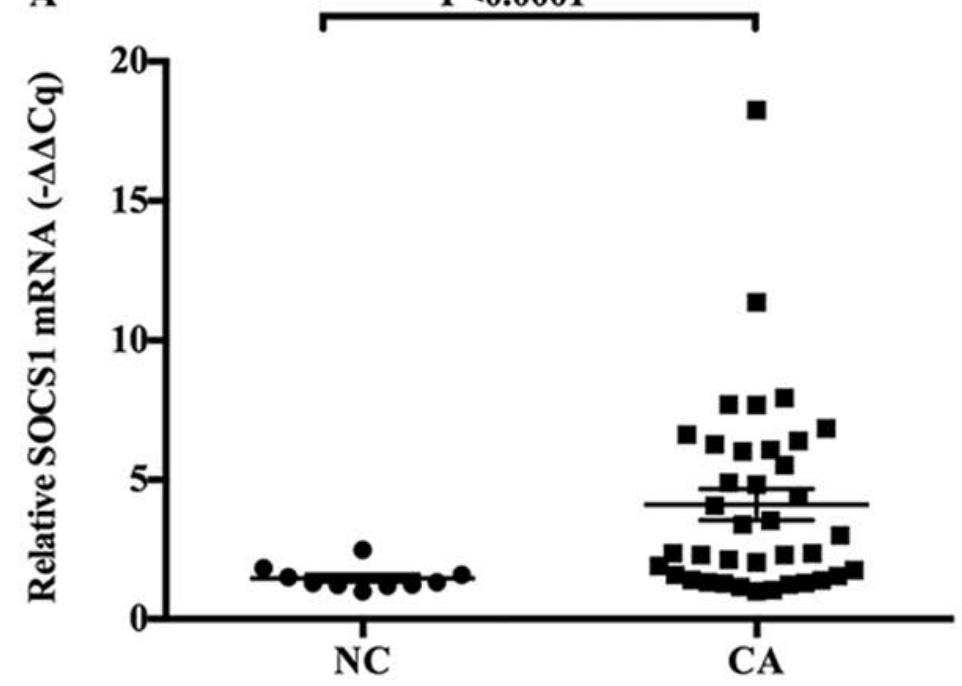

B Socs1
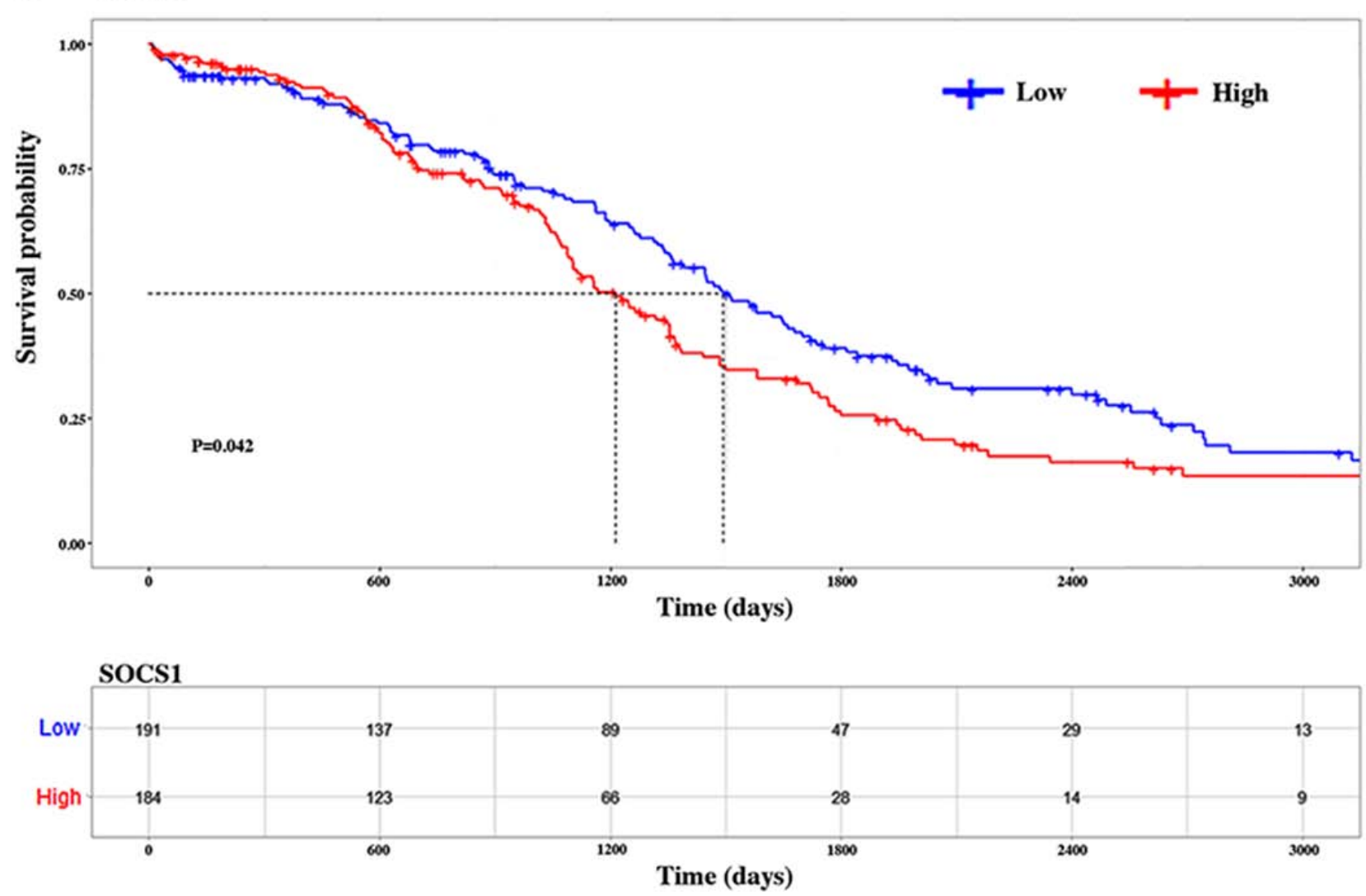

Figure 2. Relative expression of the SOCS1 mRNA in ovarian cancer specimens and normal ovarian tissues, and its association with overall survival time in ovarian cancer. (A) SOCS1 gene expression was significantly increased in ovarian cancer tissues compared with that in normal tissues, $\mathrm{P}<0.0001 \mathrm{NC}=10$ and $\mathrm{CA}=38$. (B) The results of the survival prediction table showed that SOCS1 mRNA expression in ovarian cancer is associated with overall survival time $(\mathrm{P}=0.042)$, determined using a dataset downloaded from The Cancer Genome Atlas. SOCS1, suppressor of cytokine signaling 1; NC, normal ovarian tissue; CA, ovarian cancer tissue.

bound protein via the proteasome-dependent pathway (21). The silencing of the SOCS1 gene may result from its methylation and the inactivation of the JAK/STAT signaling pathway in the negative feedback control of tumor cells (22-25). In contrast, the hypomethylation of the SOCS1 gene may restore the transcription and protein expression of the SOCS1 gene, which is able to induce the apoptosis and growth inhibition of cells $(26,27)$.
It has been reported that the expression of the SOCS1 gene is increased in breast cancer (28), prostate cancer (29), acute myeloid leukemia and other malignancies (30). However, a study by Li et al (31), the expression of SOCS1 was revealed to be decreased within the metastatic sites of malignant melanoma. In hepatocellular carcinoma, the methylation of the SOCS1 gene coexists with a deletion mutation (32). The reason for this discrepancy in the expression of SOCS1 is yet to be definitively answered, but 

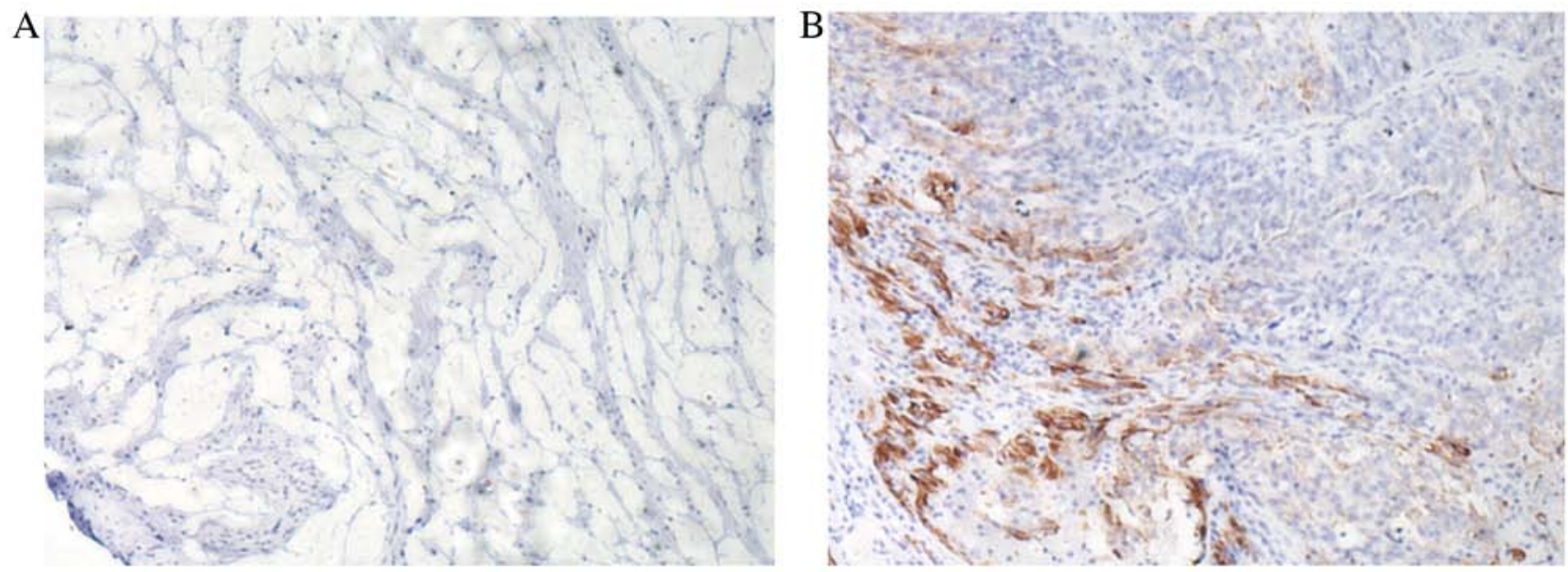

Figure 3. Expression of SOCS1 protein was detected using immunohistochemistry. Magnification x400. (A) Expression of SOCS1 in normal ovarian tissue was negative. (B) Expression of SOCS1 in the cytoplasm of ovarian cancer cells was positive. Positive SOCS1 protein staining presented brown-yellow granules, while negative SOCS1 protein staining presented light yellow granules, which were located in the cytoplasm. SOCS1, suppressor of cytokine signaling 1.

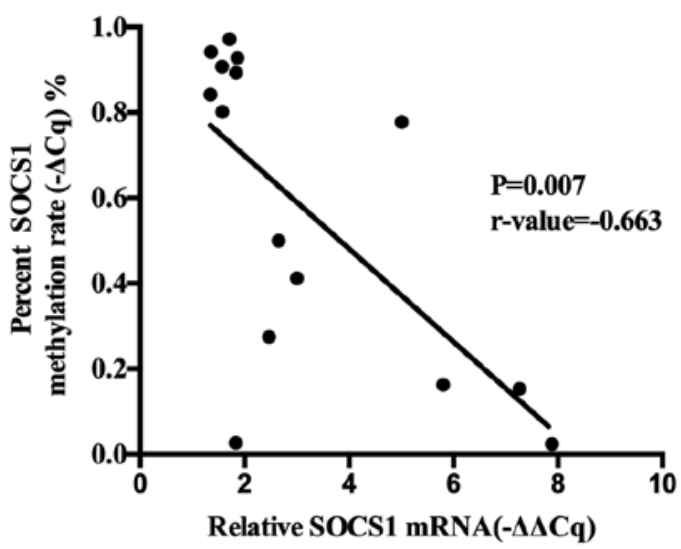

Figure 4. Correlation analysis on the methylation rate of SOCS1 and the relative expression of SOCS1 mRNA. It was revealed that SOCS1 mRNA expression and methylation rate were negatively correlated in ovarian cancer specimens and normal tissues. SOCS1, suppressor of cytokine signaling 1 .

its expression in the majority of malignancies is consistent. The SOCS1 gene is highly expressed in breast cancer and inhibits the growth of tumor cells (28). Likewise, Shimada et al (20) observed that the overexpression of the SOCS1 gene is effective for antitumor therapy by suppressing the JAK/STAT, focal adhesion kinase and epidermal growth factor receptor signaling pathways in non-small cell lung cancer. Numerous cytokines and hormones are able to affect tumor proliferation, activation and apoptosis by activating the JAK-STAT signaling pathway. For example, Yun et al (33) observed that IL-6 inhibits senescence through the activation of the JAK1-STAT3 signaling pathway. In addition, Cokic et al (34) observed that EPO-mediated proliferation and survival of erythroid progenitors occurs mainly through the modulation of JAK-STAT pathway. Likewise, the inhibition of the cytokine-dependent activation of the JAK/STAT3 pathway may also afford orthogonal treatment opportunities for other oncogene-dependent cancer cells. Among these cytokines and hormones, STAT3 serves various role in signal transduction, which has been reported in numerous cancer types including breast (35), prostate (36) and pancreatic cancer (37).
The expression of SOCS1 may be induced by the activation of STAT3. In a study by Akira (27), it was revealed that ovarian cancer cell lines and clinical specimens exhibited sustained activation of STAT3, which is able to inhibit apoptosis and promote the proliferation or metastasis of cells involved in the occurrence and progression of ovarian cancer via the JAK/STAT signaling pathway (38). Therefore, the overexpression of SOCS1 may be the result of the sustained activation of STAT3, and is able to control the development of a tumor by inhibiting JAK/STAT signaling.

At present, the mechanism of SOCS1 in ovarian cancer remains unclear. In the present study, the expression of SOCS1 in ovarian cancer specimens was increased and its methylation rate was decreased. This study did not analyze the association between SOCS1 expression and histological grading of ovarian cancer. Furthermore, the methylation rate of the SOCS1 gene negatively correlated with the relative expression of SOCS1 in ovarian cancer specimens and normal ovarian specimens. Therefore, it was deduced that the reduction of SOCS1 methylation in ovarian cancer specimens could increase the expression of SOCS1, which is to inhibit the JAK/STAT signaling pathway, and may be involved in the development and progression of ovarian cancer. It may also be that the sustained activation of STAT3 in ovarian cancer causes the high expression of SOCS1 (39), which could be adopted by the host as a protective mechanism against disease. Additionally, analysis of the TCGA gene expression datasets for a large cohort of patients with ovarian cancer was performed in the present study, where the SOCS1 expression level was associated with overall survival time (Fig. 2B), suggesting that SOCS1 may be used to determine the prognosis of patients with ovarian cancer. Due to the small sample size, this study was unable to investigate the association between SOCS1 expression level and the different clinical grades in the ovarian cancer and normal tissues. A larger sample size is required in future studies to investigate this further. In addition, in vitro investigations using ovarian cancer cell lines to detect differences in the expression of SOCS1, and further analyze the role of SOCS1 in the development and progression of ovarian cancer will also be performed. In a recent study, Nakagawa et al (40) demonstrated that the adenoviral delivery 
of SOCS1 inhibited tumor growth through the downregulation of programmed death-ligand 1 expression, resulting in the activation of tumor-infiltrating T cells. Thus, the SOCS1 gene may be a novel molecular marker and therapeutic target for ovarian cancer. Notably, the demethylation of SOCS1 CpG islands may restore the function of tumor suppressor genes, which could be a novel starting point for developing therapeutic drugs against ovarian cancer; however, further investigation into the underlying mechanisms are required.

\section{Acknowledgements}

Not applicable.

\section{Funding}

The present study was supported by the Research Progress of SOCS1 Gene in Ovarian Cancer from the National Natural Science Foundation (grant no. 81401660) and the Heilongjiang Natural Science Foundation (grant no. H201351).

\section{Availability of data and materials}

All data generated or analyzed during the present study are included in this published article.

\section{Authors' contributions}

CM and WL analyzed and interpreted data on patients with ovarian cancer. CK, YF and JL conceived and designed the experiments. AL, AZ, WS, XH and BY performed the experiments, and XL participated in the whole process of experimental research and contributed in the writing of the manuscript. All authors have read and approved the final version of the manuscript.

\section{Ethics approval and consent to participate}

Informed consent was obtained from patients and their families, and approval was granted from the HMU Medical Science Ethics Committee (approval no. HMUIRB20180006).

\section{Patient consent for publication}

Not applicable.

\section{Competing interests}

The authors declare that they have no competing interests.

\section{References}

1. Siegel RL, Miller KD and Ahmedin J: Cancer statistics, 2018. CA Cancer J Clin 68: 7-30, 2018.

2. Babon JJ, Varghese LN and Nicola NA: Inhibition of IL-6 family cytokines by SOCS3. Semin Immunol 26: 13-19, 2014.

3. Liau N, Laktyushin A, Lucet IS, Murphy JM, Yao S, Whitlock E, Callaghan K, Nicola NA, Kershaw NJ and Babon JJ: The molecular basis of JAK/STAT inhibition by SOCS1. Nat Commun 9: 1558,2018

4. Liang YB, Tang H, Chen ZB, Zeng LJ, Wu JG, Yang W, Li ZY and Ma ZF: Downregulated SOCS1 expression activates the JAK1/STAT1 pathway and promotes polarization of macrophages into M1 type. Mol Med Rep 16: 6405-6411, 2017.
5. Chan SR, Rickert CG, Vermi W, Sheehan KC, Arthur C, Allen JA, White JM, Archambault J, Lonardi S, Mcdevitt TM, et al: Dysregulated STAT1-SOCS1 control of JAK2 promotes mammary luminal progenitor cell survival and drives ER $\alpha(+)$ tumorigenesis. CDD 21: 234-246, 2014.

6. Wingelhofer B, Neubauer HA, Valent P, Han X, Constantinescu SN, Gunning PT, Müller M and Moriggl R: Implications of STAT3 and STAT5 signaling on gene regulation and chromatin remodeling in hematopoietic cancer. Leukemia 1: 1713-1726, 2018.

7. Scutti JA, Matsuo AL, Pereira FV, Massaoka MH, Figueiredo CR, Moreira DF, Belizário JE and Travassos LR: Role of SOCS1 gene on melanoma cell growth and tumor development. Transl Oncol 4: 101-109, 2011.

8. Saelee P, Chuensumran U, Wongkham S, Chariyalertsak S, Tiwawech D and Petmitr S: Hypermethylation of suppressor of cytokine signaling 1 in hepatocellular carcinoma patients. Asian Pac J Cancer Prev 13: 3489-3493, 2012.

9. Zalewski K, Doniec J, Włodzimierz W and Bidziński M: Revised FIGO staging systems for gynecologic malignancies-2009 update. Ginekol Pol 81: 778-782, 2010 (In Polish).

10. Li LC and Dahiya R: MethPrimer: Designing primers for methylation PCRs. Bioinformatics 18: 1427-1431, 2002.

11. Livak KJ and Schmittgen TD: Analysis of relative gene expression data using real-time quantitative PCR and the 2(-Delta Delta C(T)) method. Methods 25: 402-408, 2001.

12. Li C, Yang W, Zhang J, Zheng X, Yao Y, Tu K and Liu Q: SREBP-1 has a prognostic role and contributes to invasion and metastasis in human hepatocellular carcinoma. Int J Mol Sci 15: 7124-7138, 2014.

13. Therneau T: Survival: Survival analysis including penalised likelihood. https://CRAN.R-project.org/package=survival. Accessed October 2, 2018

14. R Core Team: R: A Language and Environment for Statistical Computing. R Foundation for Statistical Computing, Vienna, Austria.http://www.R-project.org. Accessed October 2, 2018.

15. Chim CS, Fung TK, Cheung WC, Liang R and Kwong YL: SOCS1 and SHP1 hypermethylation in multiple myeloma: Implications for epigenetic activation of the Jak/STAT pathway. Blood 103: 4630-4635, 2004

16. Endo TA, Masuhara M, Yokouchi M, Suzuki R, Sakamoto H, Mitsui K, Matsumoto A, Tanimura S, Ohtsubo M, Misawa H, et al: A new protein containing an SH2 domain that inhibits JAK kinases. Nature 387: 921-924, 1997.

17. Yasukawa H, Misawa H, Sakamoto H, Masuhara M, Sasaki A, Wakioka T, Ohtsuka S, Imaizumi T, Matsuda T, Ihle JN and Yoshimura A: The JAK-binding protein JAB inhibits Janus tyrosine kinase activity through binding in the activation loop. EMBO J 18: 1309-1320, 1999.

18. Babon JJ, Kershaw NJ, Murphy JM, Varghese LN, Laktyushin A, Young SN, Lucet IS, Norton RS and Nicola NA: Suppression of cytokine signaling by SOCS3: Characterization of the mode of inhibition and the basis of its specificity. Immunity $36: 239-250$, 2012.

19. Kazi JU, Kabir NN, Flores-Morales A and Rönnstrand L: SOCS proteins in regulation of receptor tyrosine kinase signaling. CMLS 71: 3297-3310, 2014.

20. Shimada K, Serada S, Fujimoto M, Nomura S, Nakatsuka R, Harada E, Iwahori K, Tachibana I, Takahashi T, Kumanogoh A, et al: Molecular mechanism underlying the antiproliferative effect of suppressor of cytokine signaling-1 in non-small-cell lung cancer cells. Cancer Sci 104: 1483-1491, 2013.

21. Kamizono S, Hanada T, Yasukawa H, Minoguchi S, Kato R, Minoguchi M, Hattori K, Hatakeyama S, Yada M, Morita S, et al: The SOCS box of SOCS1 accelerates ubiquitin-dependent proteolysis of TEL-JAK2. J Biol Chem 276: 12530-12538, 2001.

22. Yoshikawa H, Matsubara K, Qian GS, Jackson P, Groopman JD, Manning JE, Harris CC and Herman JG: SOCS1, a negative regulator of the JAK/STAT pathway, is silenced by methylation in human hepatocellular carcinoma and shows growth-suppression activity. Nat Genet 28: 29-35, 2001.

23. Galm O, Yoshikawa H, Esteller M, Osieka R and Herman JG: SOCS1, a negative regulator of cytokine signaling, is frequently silenced by methylation in multiple myeloma. Blood 101: 2784-2788, 2003.

24. Lin YC, Lin CK, Tsai YH, Weng HH, Li YC, You L, Chen JK, Jablons DM and Yang CT: Adenovirus-mediated SOCS3 gene transfer inhibits the growth and enhances the radiosensitivity of human non-small cell lung cancer cells. Oncol Rep 24: 1605-1612, 2010. 
25. Watanabe D, Ezoe S, Fujimoto M, Kimura A, Saito Y, Nagai H, Tachibana I, Matsumura I, Tanaka T, Kanegane $\mathrm{H}$, et al: Suppressor of cytokine signalling-1 gene silencing in acute myeloid leukaemia and human haematopoietic cell lines. Br J Haematol 126: 726-735, 2015.

26. Sutherland KD, Lindeman GJ, Choong DY, Wittlin S, Brentzell L, Phillips W, Campbell IG and Visvader JE: Differential hypermethylation of SOCS genes in ovarian and breast carcinomas. Oncogene 23: 7726-7733, 2004.

27. Burke WM, Jin X, Lin HJ, Huang M, Liu R, Reynolds RK and Lin J: Inhibition of constitutively active Stat 3 suppresses growth of human ovarian and breast cancer cells. Oncogene 20: 7925-7934, 2001.

28. Sasi W, Jiang WG, Sharma A and Mokbel K: Higher expression levels of SOCS 1,3,4,7 are associated with earlier tumour stage and better clinical outcome in human breast cancer. BMC Cancer 10: 178, 2010.

29. Flowers LO, Subramaniam PS and Johnson HM: A SOCS1 peptide mimetic inhibits both constitutive and IL-6 induced activation of STAT3 in prostate cancer cells. Oncogene 24: 2114-2120, 2005

30. Griffiths EA, Gore SD, Hooker CM, Mohammad HP, Mcdevitt MA, Smith BD, Karp JE, Herman JG and Carraway HE: Epigenetic differences in cytogenetically normal versus abnormal acute myeloid leukemia. Epigenetics 5: 590-600, 2010.

31. Li Z, Metze D, Nashan D, Müller-Tidow C, Serve HL, Poremba C, Luger TA and Böhm M: Expression of SOCS1, suppressor of cytokine signalling-1, in Human Melanoma. J Invest Dermatol 123: 737-745, 2004

32. Nagai H, Kim YS, Konishi N, Baba M, Kubota T, Yoshimura A and Emi M: Combined hypermethylation and chromosome loss associated with inactivation of SSI-1/SOCS1/JAB gene in human hepatocellular carcinomas. Cancer Lett 186: 59-65, 2002.

33. Yun UJ, Park SE, Jo YS, Kim J and Shin DY: DNA damage induces the IL-6/STAT3 signaling pathway, which has anti-senescence and growth-promoting functions in human tumors. Cancer Lett 323: 155-166, 2012.
34. Cokic VP, Bhattacharya B, Beleslin-Cokic BB, Noguchi CT, Puri RK and Schechter AN: Jak-STAT and AKT pathway-coupled genes in erythroid progenitor cells through ontogeny. J Transl Med 10: 116, 2012.

35. Haricharan S and Li Y: STAT signaling in mammary gland differentiation, cell survival and tumorigenesis. Mol Cell Endocrinol 382: 560-569, 2014.

36. Dallavalle C, Albino D, Civenni G, Merulla J, Ostano P, Mellogrand M, Rossi S, Losa M, D'Ambrosio G, Sessa F, et al: MicroRNA-424 impairs ubiquitination to activate STAT3 and promote prostate tumor progression. JCI 126: 4585-4602, 2016.

37. Zhang X, Ren D, Wu X, Lin X, Ye L, Lin C, Wu S, Zhu J, Peng X and Song L: miR-1266 contributes to pancreatic cancer progression and chemoresistance by STAT3 and NF- $\kappa \mathrm{B}$ signaling pathways. Mol Ther Nucleic Acids 11: 142-158, 2018.

38. Saydmohammed M, Joseph D and Syed V: Curcumin suppresses constitutive activation of STAT-3 by up-regulating protein inhibitor of activated STAT-3 (PIAS-3) in ovarian and endometrial cancer cells. J Cell Biochem 110: 447-456, 2010.

39. Cai L, Zhang G, Tong X, You Q, An Y, Wang Y, Guo L, Wang T, Zhu D and Zheng J: Growth inhibition of human ovarian cancer cells by blocking STAT3 activation with small interfering RNA. Eur J Obstet Gynecol Reprod Biol 148: 73-80, 2010.

40. Nakagawa S, Serada S, Kakubari R, Hiramatsu K, Sugase T, Matsuzaki S, Matsuzaki S, Ueda Y, Yoshino K, Ohkawara T, et al: Intratumoral delivery of an adenoviral vector carrying the SOCS1 gene enhances T cell-mediated anti-tumor immunity by suppressing PD-L1. Mol Cancer Ther 17: 1941-1950, 2018.

This work is licensed under a Creative Commons Attribution-NonCommercial-NoDerivatives 4.0 International (CC BY-NC-ND 4.0) License. 